\title{
Conduciveness of Women Social Setting in Traditional Iranian Bazaar from Functional Dimension
}

\author{
Akram Khalili ${ }^{1,2}$, Siyamak Nayyeri Fallah ${ }^{1,2}$, Mohamad Tajuddin bin Mohamad Rasdi ${ }^{1}$, Ahmad Ali Farzin $^{3}$ \& \\ Seyed Amir Mansouri ${ }^{3}$ \\ ${ }^{1}$ Department of Architecture, Faculty of Built Environment, University Technology Malaysia \\ ${ }^{2}$ Department of Architecture, Nour Branch, Islamic Azad University, Iran \\ ${ }^{3}$ Department of Architecture, College of Fine Arts, University of Tehran, Iran \\ Correspondence: Akram Khalili, Faculty of Built Environment, University Technology Malaysia, Skudai, \\ Malaysia. Tel: 60-11-353-12677. E-mail: akramkhalili_uni@yahoo.com
}

Received: January 14, 2015 Accepted: January 28, 2015 Online Published: April 30, 2015

doi:10.5539/ass.v11n12p297 URL: http://dx.doi.org/10.5539/ass.v11n12p297

\begin{abstract}
Iranian traditional Bazaars are not just physical settings for everyday commercial activities. They are places of communal life especially for women and provide the main daily sources of their outdoor recreations. The research hypothesize that there is a serious lack of sensitivity to the cultural values, especially for women within modern Iranian market places. In this regard, the aim of this research was in filling this gap and describing the relationship between women communal life and urban public spaces. To reach the aim, this study was conducted among middle-aged Iranian women within the Iranian traditional Bazaar of Isfahan (as the most public urban space in the Iranian cities). To increase the accuracy of findings, the data collection methods through triangulation were unobtrusive behavioral observation of women communal life within two selected settings, semi-structured single face to face women interviews $(n=24)$, semi-structured focus group interviews $(n=5)$, and taking photographs. In order to analyze the collected data, a qualitative content analysis and descriptive analysis were used. The finding of the research showed that the social settings of traditional Isfahan Bazaar are proper for women communal life functionally.
\end{abstract}

Keywords: traditional Iranian Bazaar, women communal life, culture, environmental quality, good urban spaces

\section{Introduction}

In its most fundamental form, culture consists of norms that shape life conditions, behavior, interactions of humans. These norms are transformed to unwritten rules over time and become common in more or less formal ways in order to control people's lifestyle and behavior. Ralph (1978) asserts that from an anthropological point of view, culture means methodology of people's lifestyle and their behavioral patterns, in a way that culture lies in the center of human behavior (Altman et al., 1980). In other words, culture is internalized through human activities and communications and is accepted in the form of lifestyle (Rapoport, 1980). That is, built environment always exist in the context of a culture and is part of it (Parsons, 1975). Thus, it can be concluded that the relationship between culture and environment is a complicated relationship in which it is not possible to determine unilateral and simple relationships. On the other hand, cultural values, influence people's understanding and viewpoint about environment and consequently influence space design (Altman et al., 1980).

Space has been defined in numerous ways in different historical eras based on social and cultural approaches (Golkaar, 2005). Space doesn't express any characteristics in its concept alone, but as soon as a group of humans start an activity in a place, the symbolic meaning of space is established. In this regard, space is a context to practice activities and human behaviors, and a place to merge imagination with reality (Khalili et al., 2014). In other word, space provides some opportunities and constraints which people choose based on their cultural criteria (Gans, 1968). Therefore, public urban spaces provide different conditions for activity formation depending on cultural framework, time and space. Using and attributing public spaces is an experience that is not the same for everyone; because variables such as age, gender, social, ethnic, and racial groups influence on how urban life is understood. To sum up and from a socio-cultural point of view, urban spaces are defined as places for outside events and communications, social interactions between different groups with dissimilar demands 
and likes (Burton et al., 2006). Public space is also defined as open-minded space, because these spaces are built for different functions such as the unpredictable, performing various activities, and the citizen's tendency to pave the way for these spaces to meet their needs (Wekerle, 2005).

\subsection{Women, Social life, and Urban Space}

Considering the fact that more than half of the population of societies consists of women and their social roles are developing, thus, it can be said that, the presence of women in urban spaces has become a necessity. Therefore, urban spaces should have some capabilities for providing an opportunity for women's presence and be supportive of women communal life. In other words, it can be said that urban spaces are very important in recognizing women's activities and social relationships, explaining the concept of space, place, and the areas where relationships are established. However, because men's and women's communal life is formed simultaneously in these spaces, conduciveness of urban spaces for women, as vulnerable people in a society, means that those spaces are also conducive for others (Kazemi Motlagh, 2010). In other words it is necessary that all groups be present in space and facilities be provided for the presence of all users regardless of their gender, age, social class, etc. (Garcia Ramon et al., 2004).

Further, the interrelationship between space and gender is expressed in an environment in the form of the reflection of gender beliefs and introvert architecture. It formulates the formation of values and closed gender roles inside closed introvert space. The structure of gender relations and the role of men and women in the type of an extrovert body, in comparison to an introvert type, have relatively open characteristics. In other words, the relationship between components in each social system is reciprocal and all phenomena are mutually and continuously interacting with each other. Therefore, spaces as a phenomenon and gender as another one mutually affect each other. In this regard, the contents related to gender have been mentioned above as one side of this relationship. Therefore, the active role of space as the context for social interactions should be considered as the other side of this relationship (Rendell, 2001). In fact, space is an active factor in the process of the formation of this structure, while it reflects the structure of gender. These spaces effectively play a role in providing a context for people's presence and its continuity, with the use of their proper features which are the result of appropriate reflection of values, culture, beliefs, and social systems (Nayyeri Fallah et al., 2015). Thus, it can be concluded that gender should be considered as a social structure and space as a physical-social structure, as two components that affect the formation of social life in urban public spaces.

\subsection{Conducive Urban Space from Environmental Quality Perspective}

The extent of social life formation and interactions between users of public urban spaces reflect the quality of a space. However, owing to improvement of spatial quality, social and optional activities also take place in the space because in this situation people are more interested in staying in the space and, therefore, there will be more time for different activities to occur (Carmona, 2008; Gehl, 2004; Whyte \& Nocera, 2002). Consequently, occurrence of various optional activities in space shows higher environmental quality of that space.

Some researchers consider environmental quality as equivalent to the fulfillment of human needs and social justice and some consider it equivalent and compatible with human environment (Lang, 1987; Lynch, 1984). In this respect, two approaches of design-oriented and plan-oriented approaches are common in the evaluation of the quality of environment, and considering the nature of the aim and theoretical framework of this study. The design-oriented approach will be applied in the analysis of the selected public spaces in this study. The attitude towards the quality of environment in the synthesized approach is to achieve the environmental features that while meeting human needs, provide the opportunity for social life to be formed in public spaces and allow for making a proper relationship between man and environment.

Based on the approach of this study, which is a combination of human and spatial needs in a design-oriented approach, environmental comfort is one of the important and fundamental components in achieving the desired communal life (Gehl, 2004; Lynch, 1984). Therefore, providing the necessary condition for comfort is one of the main parts in designing communal spaces. In other words, an attempt at achieving environmental comfort is an effort to meet human physiological needs. One of these important criteria is providing climate comfort which means the existence of shelter and protection against natural elements such as wind, rain, and sunlight. Another criterion is the existence of proper lighting solutions. This component provides the space with more capability of protecting users. The availability of proper facilities such as proper urban furniture, toilets, drinking fountains, retail shops, and food distribution are necessary. Absence of these facilities leads to absence of users (Nasution $\&$ Zahrah, 2012). It should be mentioned that these cases are more critical for encouraging women to be present continuously and use the space (Javidaani, 2012). In other words, spaces that include the necessary 
abovementioned facilities, possess a stronger functional dimension which will have a positive effect on the improvement of the level of activities in space (Alexander et al., 1977).

Hence, the three dimensional relationship between public space, comfort resulting from providing the basic condition of fulfillment of human physiological needs and the degree of space users' activities (Aydin and Ter, 2008). Another important component in providing environmental comfort is cleanliness. There is a direct relationship between this component and the users in space (Perkins \& Thorns, 2011). The viewpoint of environmental quality and achieving it fulfills and meets users' physiological needs. This condition causes people to be encouraged to be present in public spaces and so their social life is formed. These can be understood from the design-oriented spatial approach as well as the human approached mentioned before. In this regard, theorists such as Appleyard (1981), Carmona et al., (2010), Jacobs, (1995), Marcus and Francis (1997), and Tibbalds (2002), considered the component of environmental convenience as one of the proper public spatial components. In addition to, safety is one of the basic human needs. Indeed, it is considered as the second most desirable requirement after physiological needs (Lang, 1987; Maslow, 1987). Burton et al., (2006) believes that safety in communal space is produced in different levels. Therefore it can be said that safe communal space is one that is safe for all the users whether audiences, pedestrians, observers. The following figure shows the relationship of this category of space users:

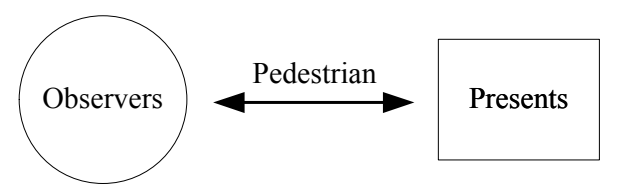

Figure 1. User classification due to communal spaces (Adapted from Burton et al., (2006))

As can be seen in the above figure, the first category of users is those whose residence or work place is somehow related to the urban space and the adjacent spaces. These types of people that include residents and workers in a space are called presents. The second category are people who are only passing by a space in order to reach another destination, they are called pedestrians. The third category called observers is people who choose space for their social life such as sitting, eating, talking, walking, etc. Therefore, the qualitative criteria considered for this research in the area of safety, are related to criteria related to environmental quality, whose capability and function improve safety in communal life.

Carmona et al., (2010) considers evaluation of the qualities of public urban spaces possible through the six dimensions including morphological, conceptual, social, visual, functional, and temporal dimensions. Based on the analyses and syntheses conducted in this study and considering the combined selected approach in design-oriented approach to analyze the quality of proper communal space for the formation of women communal life, the author suggests the four dimensions which are functional, visual social and cultural, each of which consists of the related indicators. In the following, it will be discussed the proposed functional dimension supporting the formation of women social activities in communal spaces

\subsection{Functional Dimension and Its Parameters}

The functional dimension suggested in this study consists of 3 parameters, namely, convenience, accessibility, and space fluency. Among which the convenience parameter was discussed in the above. In the following, the aspects selected for this study that will be discussed are accessibility and space fluency.

\subsubsection{Accessibility}

According to Oldenburg (1999), physical access to spaces is one of the indicators of environmental quality improvement. It means that communal spaces, while being appealing, should be accessible to all society members at all hours of the day (Carr et al., 1993; Oc and Tiesdell, 1997). Bentley (1999) expresses that the number of potential passages and accesses that are built for a space to move from one point to another, show the quality of that space. In other words, it can be said that physical access includes a person's ability to move within a space. Wood et al., (2010) and Knox et al., (2009) present some approaches in a classic theory to improve people's capability to move in a space. They emphasize improvement of public possessions in order to increase access between spaces and Wood et al., (2010) emphasizes improvement of the number of spatial relationships with the aim of increasing social interactions. Carmona et al., (2010) interprets this spatial cohesion as the change of dead-end routes to open routes. Also Movahed et al., (2012) emphasized reducing real barriers (gates, hedges, walls, etc.) and also symbolic barriers (Gardens, fences, etc.) for improvement and access. 
On the other hand, Banerjee (2001) states that available public spaces are not just accessible spaces but they should be capable of forming people's social life. Thus, that several pedestrian connections can provide opportunities for people communal interactions (Banerjee, 2001; Bentley, 1999; Jacobs, 1961; Tibbalds, 2002). In addition to the abovementioned, Carmona et al., (2010) believes that access spaces should be capable of having public transportations. This possibility allows all users especially vulnerable groups such as women and children, to be present in the space at different hours of the day (Matos Wunderlich, 2008). Based on what was mentioned, routs of public transportation and proper and numerous sidewalk access are some of the routes that can be evaluated in the parameter of accessibility.

\subsubsection{Space Fluency}

Based on space syntax theory, Hillier (1996) believes that public spaces, as variable spaces should be analyzed in a way that the flow of pedestrian movement plays a determining role in its spatial form. This attitude is very much similar to Alexander et al., (1977) theory of pattern language and also his theory of modern urbanism. It means that in terms of arrangement, physical components are not very important but connections of spaces have a determining role. This attitude is also evident in the research results of Jacobs (1961). In this area, Trancik (1986) considers maintaining continuity and combining public spaces as an important factor in creating and continuing movement in space and as a result, social activities are improved and the space becomes safer for everyone. In this regard, Hillier (1996) also considers establishing different functions through spatial connections the cause of change in movement pattern in space and believes that it improves safety.

Further, movement in public spaces forms the basis of human experience in space and is an important factor in creating and continuing life in space (Humphreys, 2010; Jacobs, 1961). In this respect, Hiller (1996) believes that people's movement in communal spaces is multifunctional. It means that besides the starting point and destination in a movement, mediating spaces are also the context of formation of communal life (Edensor, 2010). In this regard, considering the design-oriented viewpoint in this study, the parameter of space fluency will be evaluated through mobility and spatial flow measures.

\subsection{Traditional Iranian Bazaar as a Cultural Phenomenon}

Based on Edgu et al., (2012) the structure of traditional Bazaar is a combination of the fundamental physical elements (as economic, religious- cultural, social and service, and communicational and protective elements) of Bazaar and the relationships between these elements with each other. In fact, the physical elements in Iranian traditional Bazaar work as a system (Khalili et al., 2014) and they are dependent on each other while having independent identity and they form a unified set named "Bazaar". In other words, Bazaar, as a key element in Iranian-Islamic structure of cities, consists of smaller elements.

\section{Research Aim and Methodology}

The aim of this qualitative research is to identify the relationship between communal setting of traditional Iranian Bazaar and women communal life. In this regard, through Interpretivism paradigm, qualitative approach and case study strategy the communal role of these setting to support women communal life were analyzed. To increase the accuracy of findings, the data collected through multiple tactics including site observation, semi-structured single face to face and focus group interviews, and unobtrusive behavioral observation.

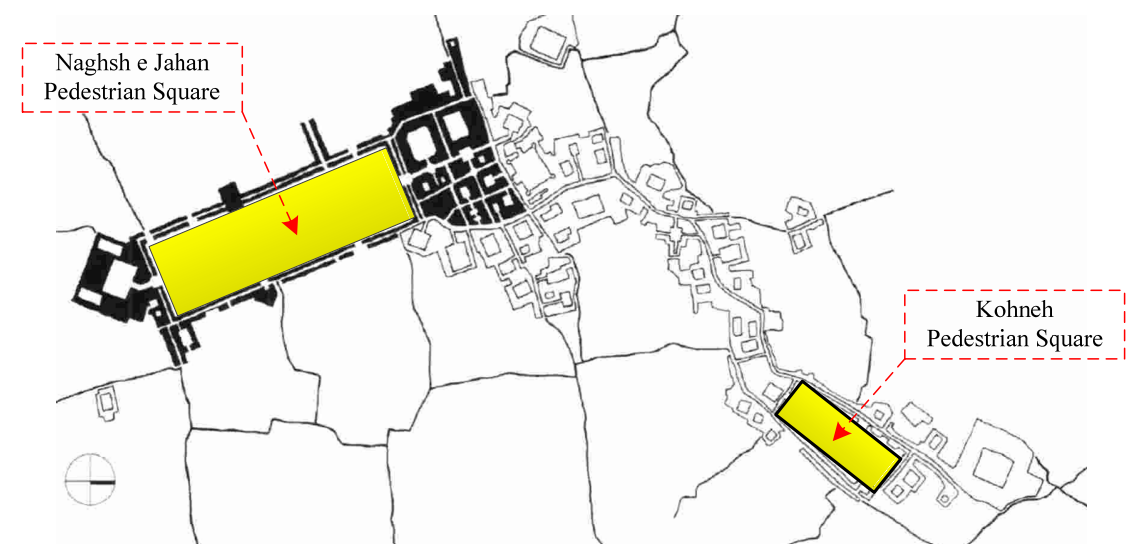

Figure 2. Two selected pedestrian squares as the women social setting in traditional Isfahan Bazaar, Iran 
In this regard, through criterion sampling strategy (Merriam, 2009), traditional Isfahan Bazaar as the common ordinary of traditional Iranian Bazaar was selected. Besides, the sampling strategy for selecting Bazaar's communal setting was purposeful. It means that after preliminary investigation the women social setting including two pedestrian squares namely Meydan Naghsh e Jahan and Meydan Kohneh in traditional Isfahan Bazaar were selected as cases of study. Additionally, the selection of participants was based on homogeneous sampling (Abolmaali, 2012) and among women of the ages of 35 to 60.

The used technique for the preliminary investigation phase of study was covert observation and pilot semi-structured interview. After this phase which was done by main researcher and two research assistants during 2 weeks, in the phase of final investigation, the researcher and 3 research assistants did unobtrusive behavioral observation the selected setting, semi-structured interview with 24 Iranian middle-aged women and 5 groups of users during 8 days (Two sector of June 2013 and Feb 2014). The time of each single face to face interview on Farsi language was around 30-35 minutes and for focus group interviewing this time became around 50-65 minutes.

\section{Results and Discussion}

After identifying the gathered information through direct observation, semi-structured single interview, and semi-structured focus group interviewing, two social spaces in the traditional Bazaar of Isfahan where women were present and which they favored, were recognized.

Table 1. Summarizing responses derived from single face to face interviewing and focus group interviewing in terms of women communal setting in the Isfahan Bazaar

\begin{tabular}{ccc}
\hline Socio setting & Groups (Number=5) & Respondents (Number=24) \\
\hline Meydan Neghsh e Jahan & 4 & 22 \\
Meydan Kohneh & 2 & 9 \\
\hline
\end{tabular}

The findings of direct observation show that two pedestrian squares of the traditional Bazaar, Meydan Naghsh e Jahan and Meydan Kohneh, involve most communal activities of middle-aged women. These findings are also confirmed by the information obtained through semi-structured single interview, and semi-structured focus group interviews. Out of the 24 respondents in the semi-structured single interviews in June 2013, 22 respondents mentioned Meydan Naghsh e Jahan and 9 to Meydan Kohneh (some of the respondents mentioned both squares) as conducive spaces for communal activities (Table 1). For the purpose of triangulation, the responses obtained through the semi-structured focus group interview show that out of the 5 groups interviewed in Feb 2014, 4 groups referred to Meydan Naghsh e Jahan as one of the conducive spaces for communal life. In addition, the results obtained through direct observation, semi-structured single and focus group interview also confirmed the photographic evidence. The following photographs have been taken by the researcher during the data collection procedure. These photos show that Meydan Naghsh e Jahan has a significant role in forming women communal life in the traditional Iranian Bazaar.
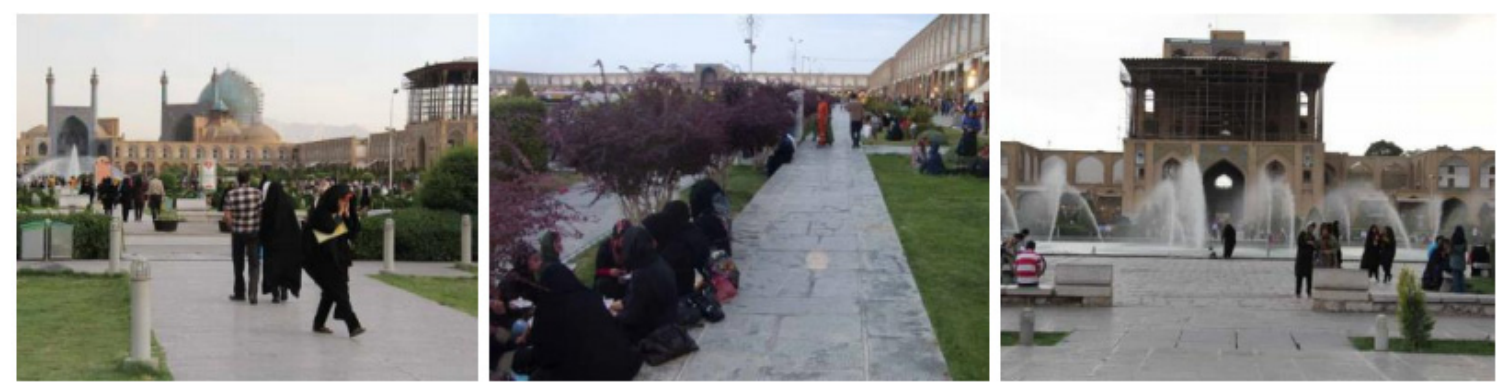

Figure 3. Women presence within Meydan Naghsh e Jahan, Traditional Isfahan Bazaar, Iran

The second social setting that was mentioned by $38 \%$ of the respondents ( 9 out of 24 people) was Meydan Kohneh which is located north of the traditional Bazaar of Isfahan. This square is located in the vicinity of Masjid Jame (Atigh), Imam Zadeh Haruniyeh, and Raasteh Enghelab. This square is completely pedestrianized and is smaller than Meydan Naghsh e Jahan in size $\left(250 \times 90 \mathrm{~m}^{2}\right)$. Besides, the responses obtained through the semi-structured focus group interview which was carried out in Feb 2014 confirm these findings. It means that 2 out of 5 groups that were interviewed considered Meydan Kohneh as one of the best women communal spaces 
(Table 1). In addition, the photographs taken from Meydan Kohneh at different times suggest women's interest in this space as a conducive space for their communal activities.
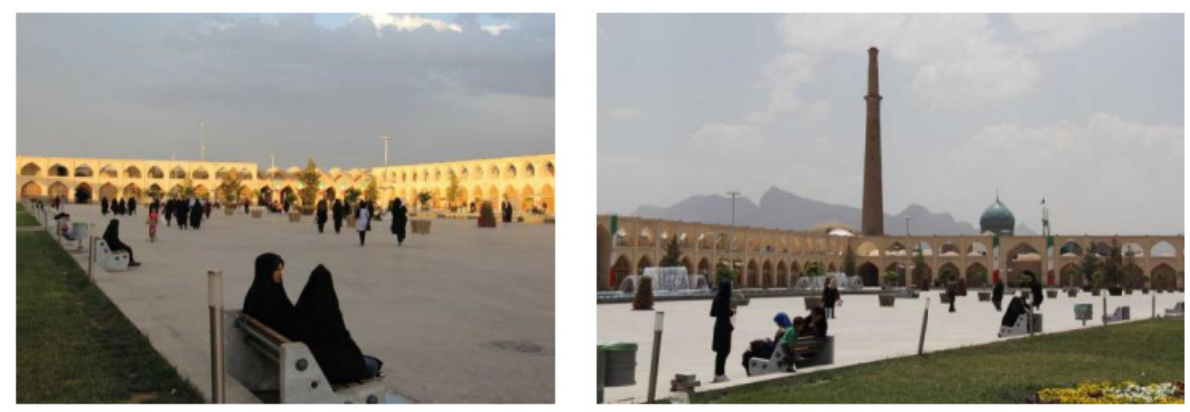

Figure 4. Women presence within Meydan Kohneh, Traditional Isfahan Bazaar, Iran

\subsection{Analysis of the Women Conducive Communal Spaces from Functional Dimension}

The parameters of accessibility, physiological convenience, and space fluency act as functional dimension in this study. Each mentioned parameters have some measures which are very helpful to clarify the framework of this study. In this regard the parameter of accessibility consists of two measures of public transportation and sidewalk access. The result of these two measures is the continuous use of public spaces which is one of the features of a safe public space. The parameter of convenience consists of four measures which are cleanliness (free of any pollution), climate comfort (protection against wind, rain, and sun), equipment and furniture, and lack of interrupting motor vehicle. Also the parameter of space fluency consists of two measures including mobility and spatial flow, where mobility is considered to mean possibility to reach various functions through pedestrian movement.

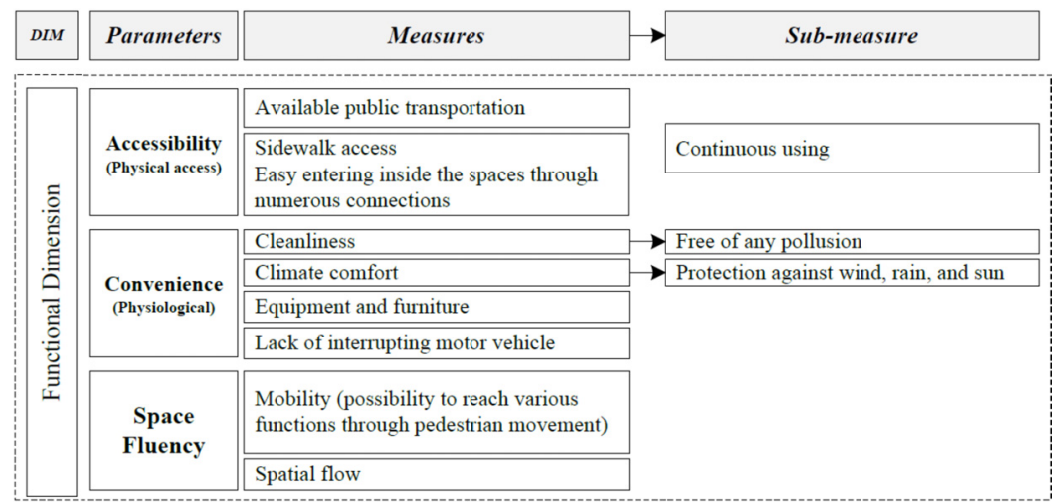

Figure 5. Parameters and measures of women conducive women communal setting from functional dimension

Based on the analysis of the data collected by semi-structured interviews with middle-aged women in the traditional Bazaar, the results related to parameters and measures of functional dimension are presented in the table below:

Table 2. Summarizing semi-structured single and group interviews responses in terms of functional dimension

\begin{tabular}{|c|c|c|c|c|c|}
\hline \multicolumn{6}{|c|}{ Summarizing Semi-structured Interviews Responses (Functional Dimension) } \\
\hline Parameters & Measures & Responses $(\mathrm{N}=24)$ & Responses $(\%)$ & Responses (Group $=5)$ & Responses $(\%)$ \\
\hline \multirow{2}{*}{ Accessibility } & Public transportation & 11 & $45.5 \%$ & 1 & $20 \%$ \\
\hline & Sidewalk access & 18 & $75 \%$ & 5 & $100 \%$ \\
\hline \multirow{4}{*}{ Convenience } & Cleanliness & 20 & $83 \%$ & 5 & $100 \%$ \\
\hline & Climate comfort & 24 & $100 \%$ & 5 & $100 \%$ \\
\hline & Furniture \& equipment & 24 & $100 \%$ & 5 & $100 \%$ \\
\hline & Lack of motor vehicle. & 3 & $12.5 \%$ & --- & --- \\
\hline \multirow{2}{*}{ Space Fluency } & Mobility & 13 & $54 \%$ & 5 & $100 \%$ \\
\hline & Spatial flow & 17 & $71 \%$ & 5 & $100 \%$ \\
\hline
\end{tabular}


As can be seen in the above table, from the viewpoint of importance of accessibility parameter, 11 of the interviewees $(45.5 \%)$ mentioned the importance of public transportation and $18(75 \%)$ to the importance of sidewalk access. Because the traditional Bazaar is connected to the residential context from each side as the backbone of the city and this fact increases the importance of the sidewalk access. On the other hand, the linear extent of the Bazaar allows citizens to access it on foot from different places. Besides, all the participants in semi-structured single interviews mentioned the importance of convenience. All the participating women consider the measure of climate comfort as one of the architectural features of Iranian traditional Bazaar in their response to question 5 of the interview (The possibility of using Bazaar in all the seasons). This is because the Iranian traditional Bazaar is roofed with suitable ventilation and natural and sufficient light which provides a suitable condition for people's use in different weather conditions. Another measure that all of the participants mentioned as a factor encouraging presence of women was the existence of proper equipment such as restrooms, stores and food and snack stalls, etc. and also furniture that suit women's needs such as proper benches, platforms, dents in the walls of Bazaar for sit-rest and especially chit chatting. In the meantime, 17 of the participants believed the necessity of improving equipment and furniture in the spaces of the traditional Bazaar of Isfahan. In this regard 20 of the participants in the interviews mentioned cleanliness as an important criterion for women while choosing public spaces and among them, 9 of the participants believed in the necessity of improving cleanliness of Bazaar.

As can be seen in Table 2, most participants (20 cases) considered the measure of motor vehicle traffic in the spaces of Bazaar as a weakness. It means that this factor can be discussed as one of the weaknesses of the spaces of the traditional Bazaar. This case is also confirmed by the information collected through direct observation. The third parameter in functional dimensions is space fluency that 17 of the interviewees $(71 \%)$ considered spatial flow and $13(54 \%)$ considered mobility as the effective factor in encouraging women to be present in communal spaces of Bazaar. For triangulation, the results of observations and semi-structured single interviews can be confirmed with the results of semi-structured focus group interviews. As can be seen in the table 2, except for public transportation which shows the importance of pedestrian movement in the space and similarly the existence of motor vehicle which shows the weakness of the traditional Bazaar, other items have been mentioned by every group. Therefore by analyzing the results of focus group interviews, the results associated with the functional dimension resulting from these interviews show the importance of improving cleanliness and equipment/furniture and also decreasing the presence of motor vehicles in the spaces of the Bazaar.

\subsection{Discussion on the Related Parameters of Functional Dimension in the Identified Social Setting}

The findings of this study show that the pedestrian squares in the Bazaar of Isfahan are very popular among most of the users and specially women owing to easy accesses. In this respect, the findings show that several connections from pedestrian squares in Bazaar of Isfahan to different spaces and pedestrian access to every parts of it on the one hand, and existence of various facilities for public transportation in these spaces have caused these pedestrian squares to be used by women all day and without any restrictions. Moreover, lack of motor vehicles in these squares has increased women's convenience in these spaces. These measures, as well as the identified measures in convenience parameter provide a strong functional dimension for increased presence of women in space and formation of different activities, while satisfying women physiological, safety, and social needs. Moreover, because of the proper proximity of pedestrian squares to roofed Raastehs, women can use them in all seasons. In additions, suitable equipment such as urban furniture, restrooms, watering place (Water dispenser), and retail stores and also food distribution are the necessary cases that are found in these squares frequently. Therefore, due to the convenient resulting from these parameters, the quality of women social life and level of their activities in these spaces have improved.

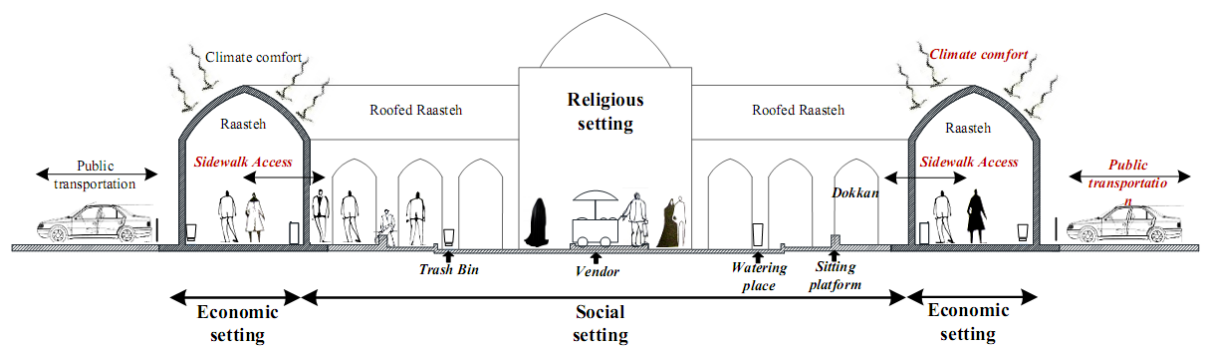

Figure 6. Section analysis of the parameters related to the functional dimension in social setting of traditional Bazaar 
On the other hand, spatial continuity in pedestrian squares, leads to continuous movement of the users. And as a result, social activities develop and the space becomes safer and more suitable for women. Because movement in public space forms the basis of women's experience of space and is an important factor in creating and continuing life in space. The following figure demonstrates the parameters related to the functional dimension in the social spaces selected by women in the traditional Bazaar.
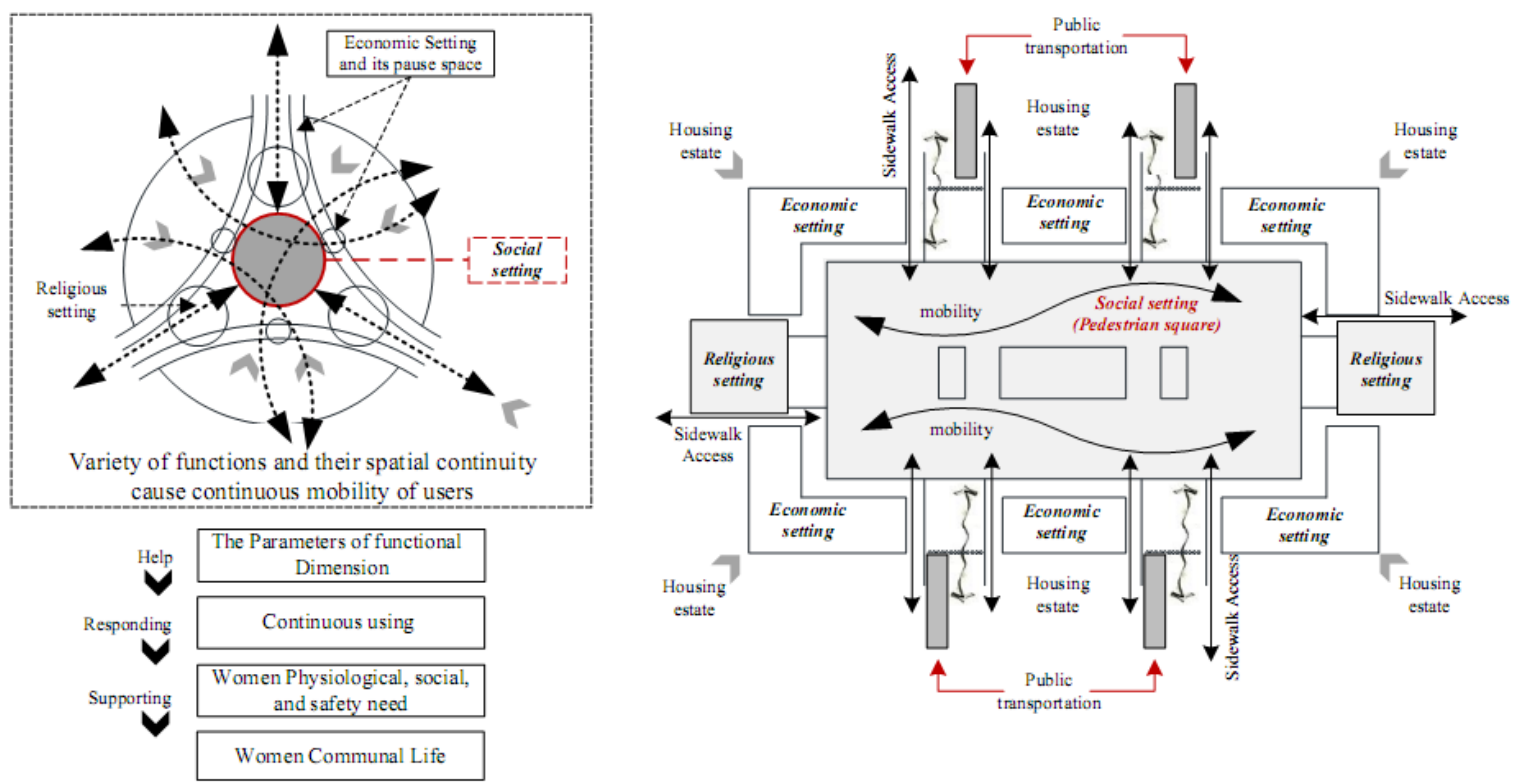

Figure 7. Analysis of the parameters related to the functional dimension in selected social setting of traditional Isfahan Bazaar

\section{Conclusion}

Based on this study, the Iranian traditional Bazaars are ideal spaces for women communal life functionally. The findings of this research show that enacting the suggested measures of the parameters of functional dimension like accessibility (Sidewalk access and public transportation), convenience (Climate comfort, cleanliness, furniture and equipment, and lack of motor vehicle), and space fluency (Mobility and spatial flow) is very helpful and necessary in improving environmental quality for the formation of women communal life. To sum up, it can be concluded that the planners and designers could have a better idea in planning and designing modern market places through considering gender role and different needs (social, cultural, safety and physiological needs) associated with it.

\section{References}

Abolmaali, K. (2012). Qualitative Research from Theory to Practice (1st ed.). Tehran: Science Press.

Alexander, C., Ishikawa, S., Silverstein, M. M., Jacobson, M., Fiksdahl-King, I., \& Angel, S. (1977). A Pattern Language: Town, Buildings, Construction. New York: Oxford University Press.

Altman, I., Rapoport, A., \& Wohlwill, J. F. (1980). Human Behavior and environment : Advances in Theory and Research. New York, NY: Springer.

Appleyard, D. (1981). Livable Streets. Berkeley: University of California.

Aydin, J., \& Ter, U. (2008). Outdoor Space Quality: Case Study of A University Campus Plaza. Archnet-IJAR, International Journal of Architectural Research, 2(3).

Banerjee, T. (2001). The future of public space: Beyond invented streets and reinvented places. APA Journal, 67, 9-24. http://dx.doi.org/10.1080/01944360108976352

Bentley, I. (1999). Urban Transformations: Power, People and Urban Design. London: Routledge.

Burton, E., \& Mitchell, L. (2006). Enclusive urban design; Street for life. London: Architectural Press.

Carmona, M. (2008). Public Space: The Management Dimension. London: Taylor \& Francis.

Carmona, M., Heath, T., Oc, T., \& Tiesdell, S. (2010). Public Places; Urban Spaces, the dimensions of urban design (2nd ed.). Oxford: Elsevier Ltd. 
Carr, S., Francis, M., \& Rivlin, L. G. (1993). Public Space (p. 420). Cambridge: Cambridge University Press.

Edensor, T. (2010). Walking in rhythms: place, regulation, style and the flow of experience. Visual Studies, 25(1), 69-79. http://dx.doi.org/10.1080/14725861003606902

Edgu, E., Unlu, A., Salgamcioglu, M. E., \& Mansouri, A. (2012). Traditional Shopping : A Syntactic Comparison of Commercial Spaces in Iran and Turkey. In J. R., \& A. C. M. Greene (Eds.), Eighth International Space Syntax Symposium (pp. 1-24).

Gans, H. J. (1968). People and Plans: Essays on Urban Problems and Solutions (p. 412). Basic Books.

Garcia Ramon, M. D., Ortiza, A., \& Parts, M. (2004). Urban planning, gender , and use of public space. Cities, 21(3), 215-223. http://dx.doi.org/10.1016/j.cities.2004.03.006

Gehl, J. (2004). Public spaces public life. Copenhagen, Denmark: Architectural Press.

Golkaar, K. (2005). Evaluation of space in urban design. Soffeh, 40, 91-103.

Hillier, B. (1996). Cities as Movement Systems. Urban Design International, 1. http://dx.doi.org/10.1057/udi. 1996.5

Humphreys, L. (2010). Mobile social networks and urban public space. New Media and Society, 12(5), 763-778. http://dx.doi.org/10.1177/1461444809349578

Jacobs, A. B. (1995). Great Streets. Masachusetls: MIT press.

Jacobs, J. (1961). The Death and Life of Great American Cities (1st ed.). New York.

Javidaani, N. (2012). Women and Urban Spaces. The Journal of Soffeh, 12(6), 57-59.

Kazemi Motlagh, N. (2010). Urban public spaces from the perspective of the social desirability of particular groups (women). People and Culture, (9), 121-132.

Khalili, A., Nayyeri Fallah, S., \& Ismail, A. sabrina. (2014). Spatial Organization of Islamic- Iranian Bazaars, Symbol of Privacy in Women's Communal Life. In 1st International Congress on Culture and Religious Thought (Vol. 8, pp. 84-92.). Qom, Iran: Cultural Institude of Safiran Mobin. Retrieved from http://safiranmobin.xzn.ir

Khalili, A., Nayyeri Fallah, S., Rasdi, M. T., \& Farzin, A. A. (2014). Women Communal Life within Iranian Traditional Bazaar from the aspect of Safety (Case study: Traditional Bazaar of Isfahan). Advances in Natural and Applied Sciences, 8(9), 94-100. Retrieved from http://www.aensiweb.com/old/anas/Aug 2014/94-100.pdf

Knox, P., \& Pinch, S. (2009). Urban Social Geography: An Introduction (6th ed., p. 392). Routledge.

Lang, J. (1987). Creating Architectural Theory: The Role of the Behavioral Sciences in Environmental Design. New York: Van Nostrand Reinhold.

Lynch, K. (1984). A Theory of Good City Form (p. 524). Cambridge, Mass: The MIT Press.

Marcus, C. C., \& Francis, C. (Eds.). (1997). People Places: Design Guidlines for Urban Open Space (2nd ed.). New York: John Wiley and Sons.

Maslow, A. H. (1987). In R. D. Frager, \& J. Fadiman (Eds.), Motivation and Personality. London: Longman.

Matos Wunderlich, F. (2008). Walking and Rhythmicity: Sensing Urban Space. Journal of Urban Design, 13(1), 125-139. http://dx.doi.org/10.1177/1461444809349578

Merriam, S. B. (2009). Qualitative Research: A Guide to Design and Implementation (2nd ed.). New York: Jossey-Bass.

Movahed, S., Azad, S. P., \& Zakeri, H. (2012). A Safe Pedestrian Walkway; Creation a Safe Public Space Based on Pedestrian Safety. Procedia - Social and Behavioral Sciences, 35(December 2011), 572-585. http://dx.doi.org/10.1016/j.sbspro.2012.02.124

Nasution, A. D., \& Zahrah, W. (2012). Public Open Space Privatization and Quality of Life, Case Study Merdeka Square Medan. Procedia - Social and Behavioral Sciences, 36(June 2011), 466-475. http://dx.doi.org/10.1016/j.sbspro.2012.03.051

Nayyeri Fallah, S., Khalili, A., \& Rasdi, M. T. (2015). Cultural Dimensions of Housing Entrance Spaces: Lessons for Modern HDVD Housing. Journal of Applied Sciences, 15(2), 173-183. http://dx.doi.org/10. $3923 /$ jas.2015.173.183 
Oc, T., \& Tiesdell, S. A. (1997). Safer City Centres: Reviving the Public Realm. New York: SAGE Publications Ltd.

Oldenburg, R. (1999). The Great Good Place (2nd ed.). New York: Marlow and Company.

Parsons, T. (1975). The present status of "structure-functional" theory in sociology. In L. A. Coser (Ed.), The idea of social structure (pp. 67-83). New York: Harcourt Brace and Jovanovich.

Perkins, H., \& Thorns, D. C. (2011). Place, Identity and Everyday Life in a Globalizing World (p. 224). Palgrave Macmillan.

Ralph, E. (1978). Human Behavior in the Social Environment; a social systems approach (2nd ed.). Chicago, Illinois, U.S.A.: Aldine Publishing Company.

Rapoport, A. (1980). Cross-cultural aspects of environmental design. In I. Airman, A. Rapoport, \& J. F. Wohlwill (Eds.), Human behavior and environment: Advances in theory and research: Vol. 4; Culture and environment (pp. 7-46). New York: Plenum Press.

Rendell, J. (2001). Pursuit of Pleasure: Gender, Space and Architecture in Regency London. London: The Athlone Press.

Tibbalds, F. (2002). Making People Friendly Towns: Improving the public environment in Towns and Cities (illustrate.). Longman: Taylor \& Francis.

Trancik, R. (1986). Finding Lost Space, Theory of Urban Design. New York: Van Nostrand Reinhold Company Inc.

Wekerle, G. (2005). Gender and the Global City: Urban Restructuring, Social Exclusion and Claims for Justice. In H. Hiller (Ed.), Urban Sociology in Canada. Toronto: Oxford University Press.

Whyte, W. H., \& Nocera, J. (2002). The organization man (New ed., p. 448). philadelphia: University of Pennsylvania. http://dx.doi.org/10.9783/9780812209266

Wood, L., Frank, L. D., \& Giles-Corti, B. (2010). Sense of community and its relationship with walking and neighborhood design. Social Science \& Medicine (1982), 70(9), 1381-1390. http://dx.doi.org/10.1016/j.socscimed.2010.01.021

\section{Copyrights}

Copyright for this article is retained by the author(s), with first publication rights granted to the journal.

This is an open-access article distributed under the terms and conditions of the Creative Commons Attribution license (http://creativecommons.org/licenses/by/3.0/). 